\title{
O Agroamigo (Pronaf B): Aspectos Operacionais no Nordeste Brasileiro
}

\author{
O Agroamigo (Pronaf B): Operational Aspects in Northeast Brazil
}

\section{O Agroamigo (Pronaf B): Aspectos Operativos en el Noreste de Brasil}

Diana Mendonça de Carvalho -https://orcid.org/0000-0001-5934-8165 ${ }^{1}$

\footnotetext{
${ }^{1}$ Doutora pelo Programa de Pós-graduação em Geografia (PPGEO)/Universidade Federal de Sergipe (UFS) - Brasil, dianamendoncadecarvalho@gmail.com
}

Recebido em: 06/05/2020

Aceito para publicação em: 30/09/2020

\begin{abstract}
Resumo
O espaço rural brasileiro passou por várias transformações nas últimas três décadas, estimulando o debate e estudo em torno da relação Estado/Espaço/Território/Agricultura Familiar e Desenvolvimento Rural. Diante disso, analisou-se a aplicação do microcrédito do PRONAF B, a partir do institucionalismo da metodologia do Agroamigo, demonstrando sua forma de operacionalização e seus impactos na região Nordeste do Brasil. Tal análise foi realizada mediante revisão bibliográfica e dados secundários advindos do Instituto Brasileiro de Geografia e Estatística (IBGE, 2006/2017) e do Banco do Nordeste do Brasil (BNB). A metodologia do Agoramigo, executada exclusivamente pelo Banco do Nordeste, com acompanhamento de assessores, possibilitou melhorias produtivas e de renda, não só agrícolas; como também, diminuiu desigualdades em termos de gênero no meio rural.
\end{abstract}

Palavras-chave: Agroamigo. Agricultor Familiar. Estado e Renda.

\begin{abstract}
The Brazilian rural space has undergone several transformations in the last three decades, stimulating debate and study around the relationship between State / Space / Territory / Family Agriculture and Rural Development. Therefore, the application of PRONAF B microcredit was analyzed, based on the institutionalism of the Agroamigo methodology, demonstrating its form of operation and its impacts in the Northeast region of Brazil. Such analysis was carried out through bibliographic review and secondary data from the Brazilian Institute of Geography and Statistics (IBGE, 2006/2017) and from Banco do Nordeste do Brasil (BNB). The Agoramigo methodology, carried out exclusively by Banco do Nordeste, with the assistance of advisors, enabled productive and income improvements, not only in agriculture; as well, it has reduced gender inequalities in rural areas.
\end{abstract}


Keywords: Agribusiness. Family Farmer. State and Income.

\section{Resumen}

El espacio rural brasileño ha sufrido varias transformaciones en las últimas tres décadas, estimulando el debate y el estudio en torno a la relación entre Estado / Espacio / Territorio / Agricultura familiar y Desarrollo rural. Por lo tanto, se analizó la aplicación del microcrédito PRONAF B, con base en el institucionalismo de la metodología Agroamigo, demostrando su forma de operación y sus impactos en la región noreste de Brasil. Dicho análisis se llevó a cabo mediante una revisión bibliográfica y datos secundarios del Instituto Brasileño de Geografía y Estadística (IBGE, 2006/2017) y del Banco do Nordeste do Brasil (BNB). La metodología de Agoramigo, realizada exclusivamente por el Banco do Nordeste, con la asistencia de asesores, permitió mejoras productivas y de ingresos, no solo en la agricultura; además, ha reducido las desigualdades de género en las zonas rurales.

Palabras clave: Agronegocios. Agricultores familiares. Estado e Ingresos.

\section{Introdução}

O espaço rural brasileiro passou por várias transformações nas últimas três décadas (valorização da agricultura familiar, tecnologia e modernização etc.). A referida dinâmica estimulou o debate e estudos em torno da relação Estado/Espaço/Território e Desenvolvimento Rural, proporcionando novas formas de se pensar o prisma da sustentabilidade em especial, no que se refere às políticas públicas implantadas na agricultura familiar. Esse setor historicamente excluído das políticas públicas implantadas na agricultura ao longo dos anos, tornou-se dentro da dimensão capitalista de produção, uma modalidade considerada atrasada, pouco produtiva e problemática no espaço rural brasileiro, mas que para sobreviver se subordina a agricultura capitalizada.

Segundo Schneider (2001), os debates sobre agricultura familiar provêm de dois momentos ímpares. O primeiro diz respeito à adoção da expressão "agricultura familiar" na conjunção das políticas públicas no contexto dos movimentos sociais do campo e das organizações rurais. Nesses debates, a agricultura familiar emerge como uma nova categoriasíntese efetivada pela Confederação Nacional dos Trabalhadores Agrícolas - CONTAG. O segundo sobressaí após criação do Programa Nacional de Fortalecimento da Agricultura Familiar - PRONAF, se configurando uma afirmação dessa nova categoria no cenário social. 
Até 1994, não havia recursos direcionados para o financiamento da agricultura familiar no Brasil. O agricultor familiar estava inserido na categoria de pequeno produtor, ou melhor, "mini produtor" para efeito de enquadramento no Manual de Crédito Rural. O produtor familiar disputava o crédito com os demais produtores, enfrentando as mesmas rotinas bancárias, seguindo os mesmos procedimentos, aplicando-se a legislação exigida para obter os financiamentos. Assim, em 1995, surge o Programa Nacional de Fortalecimento da Agricultura Familiar (PRONAF), que fora destinado aos agricultores familiares. Tal política voltava-se ao aumento da renda e a melhoria das condições de vida dos agricultores familiares. Após 25 anos de execução, não cabe nenhuma dúvida sobre a expressividade do programa, pois o mesmo se estendeu de forma considerável por todo o território nacional, em termos de crédito, com o desenvolvimento de programas especiais, assumindo a assistência técnica e reforçando a infraestrutura, tanto dos próprios agricultores, como dos municípios atendidos.

Em 2005, após realização de diagnóstico do segmento do PRONAF pelo Banco do Nordeste do Brasil, observou-se a existência de características e necessidades especiais para o agricultor familiar. Tal diagnóstico evidenciou os impactos da modalidade mais universalizada do sistema PRONAF, a modalidade B (Agroamigo) no espaço rural nordestino, por envolver características bem distintas em relação as outras modalidades, em função da amplitude social. Nessa condição, qualquer pequeno agricultor de base familiar, que tenha renda anual de até $\mathrm{R} \$ 23$ mil reais, poderá ter acesso ao financiamento de no máximo $\mathrm{R} \$$ 5.000,00 por operação pelo Agroamigo e de R\$ 2,5 mil, sem o Agroamigo, para o desenvolvimento de atividades não agrícolas (BNB, 2019).

O PRONAF B é ainda a modalidade que apresenta maior número de contratos voltado ao pobre dos mais pobres do meio rural brasileiro. Caracteriza-se como um crédito orientado face à aplicação de metodologia inovadora, particularmente para a região Nordeste, chamada Agroamigo que é o Programa de Microfinança Rural do Banco do Nordeste. Tal metodologia atende, de forma pioneira no Brasil, a milhares de agricultores (as) familiares. O Agroamigo se propõe a melhorar os perfis econômico e social do (a) agricultor (a) familiar de mais baixa renda no Nordeste e norte de Minas Gerais, por meio de metodologia própria, cuja principal característica é a forte presença do Assessor de Microcrédito Rural nas comunidades, a concessão de crédito orientado e acompanhado.

Os estudos dos impactos do PRONAF, principalmente os da modalidade B, apresentam um conjunto diverso de interpretações científicas. Mattei (2005) analisa a importância desses estudos, quando reúne as principais contribuições científicas geradas a 
partir dos resultados do programa em todo o Brasil, agregando teses, dissertações, artigos científicos, livros e capítulos de livros, além dos relatórios de pesquisa.

Na mesma esteira, são as abordagens de Bittencourt (2003;2005) e Abramovay (2001), cujos autores analisam os processos de inovação institucional aplicados no financiamento da agricultura familiar a partir de estudos de caso. Aliás também, Abramovay (2001) trabalha às finanças de proximidade e sua inserção em regiões pobres do semiárido nordestino. Sobre os impactos do PRONAF B (Agroamigo) no meio rural na região Nordeste, é pertinente o relatório de pesquisa realizado por SILVA e outros (2007) constituído pelo arranjo institucional observado em dois estados nordestinos, bem como a análise acerca da percepção dos tomadores de crédito e dos fatores positivos e negativos relacionados a essa modalidade de financiamento.

Sendo assim, torna-se necessário analisar a modalidade de Crédito PRONAF B, quando da aplicação da metodologia do Programa Agroamigo, demonstrando sua forma de operacionalização e seus impactos preliminares na região Nordeste do Brasil. Essa análise será realizada mediante revisão bibliográfica de autores que trabalham temáticas relacionadas a agricultura familiar, desenvolvimento rural territorial e sustentável; além claro, do foco no PRONAF, enquanto política pública. Nesse são utilizados ainda, dados secundários advindos do Instituto Brasileiro de Geografia e Estatística (IBGE, 2006/2017) e do Banco do Nordeste do Brasil (BNB).

Apesar da perda de representatividade frente ao Censo de 2006 (IBGE, 2006), quando o número total de estabelecimentos de agricultores familiares no Brasil era de 4.367.902; no Censo Agropecuário de 2017 (IBGE, 2017), o número caiu para 3.897.408 estabelecimentos, representando 76,82\% da totalidade de estabelecimentos no Brasil (5.073.327). A perda em relação a representatividade de estabelecimentos da agricultura familiar foi de 10,8\% de um censo ao outro. Pelos dados do Censo Agropecuário (IBGE, 2017), o Nordeste continua sendo a região com maior número de unidades familiares: 1.838 .846 (47,2\%); nas demais regiões do país, a distribuição das unidades é a seguinte: Sudeste 688.945 (17,7\%), Sul 665.767 (17,1\%), Norte 480.575 (12,3\%) e Centro-Oeste 223.275 (5,7\%).

Entretanto, 36,20\% dos agricultores familiares brasileiros são proprietários de um lote menor que cinco hectares. A região Nordeste é a que apresenta o maior número de minifúndios, com 51,2\% de unidades familiares no extrato inferior a 5 hectares (IBGE, 2017). Pelos dados catalogados no Censo Agropecuário (IBGE, 2017), é possível validar intensificação da concentração de terras no Brasil em grandes áreas, haja vista, apenas 22,5\% dessa serem ocupadas por proprietários da agricultura familiar. No Censo anterior (IBGE, 
2006), a posse da agricultura familiar, quanto a estabelecimentos com menos de 5 hectares representava $24,3 \%$.

O retrato dessa concentração justifica-se na insegurança do pequeno agricultor sobreviver no campo, não só financeiramente, mas também pelo acréscimo de violência. Muitos desses acabam migrando para a cidade, que é mais atrativa, desfazendo-se da terra e indo coabitar em bolsões de pobreza, devido à dificuldade de se inserir no mercado formal.

\section{A Agricultura Familiar como Foco de Política Pública e Desenvolvimento Rural.}

A agricultura familiar é responsável pela produção dos principais alimentos consumidos pela população brasileira, além de representar $90 \%$ da ocupação da mão de obra rural nacional. Fato que demonstra a importância em existir políticas públicas voltadas aos agricultores familiares, seja pelo número de estabelecimentos rurais desse segmento, seja pela quantidade de brasileiros que vivem em área rural ou pela importância da produção familiar em relação ao valor bruto da produção agropecuária nacional. Contexto que fundamenta o alcance social do Agroamigo (PRONAF B), voltados a esses atores sociais.

Como se conhece a agricultura brasileira, nos tempos coloniais, fundava-se basicamente sob a grande propriedade, a monocultura e o trabalho escravo. Esses pilares davam suporte a geração de lucros que eram incessantemente, maximizados, a fim de possibilitarem bons resultados financeiros (Prado Júnior, 2004).

Com base nessas variáveis, o cultivo da cana-de-açúcar constituiu-se num investimento de alta rentabilidade, dados os altos preços de seus derivados no mercado internacional, em face de os fatores de produção se afigurarem relativamente baratos. Assim, a cana-de-açúcar se expandiu, de forma especial, ao longo da região Nordeste do país.

Ao analisar esse assunto, constata-se que a agricultura brasileira possui um perfil próprio e peculiar, considerando que foi constituída, desde os tempos do Brasil Colonial, para atender ao mercado externo, tendo com base o plantio de grandes lavouras. Aspecto contrário ao observado entre os países europeus, que desde muito privilegiaram a pequena produção familiar.

Entretanto, desde o início da década de quarenta do século XIX, Caio Prado Junior (2004) registrava que, apesar do Brasil ter superado o período colonial, mantinha inalterada a 
conjuntura agrária. Fato que dificultava o acesso do trabalhador rural à economia formal, concentrando progressivamente a modernização, a terra e gerando massa de "sem terras".

Furtado (1980) ao analisar esse momento da história econômica do Brasil, observa que, naquela época, os grandes proprietários brasileiros detinham o controle de três quartos da oferta mundial do café, o que lhes possibilitavam administrar os preços e a rentabilidade desse produtor, através da produção disponibilizada ao mercado interno.

No Governo Juscelino Kubitschek, outra questão importante, afirmava-se nas deficiências do processo de comercialização. Problema que ao longo do Governo, foram superados, com a construção de depósitos para o armazenamento, e com a expansão do sistema rodoviário nacional.

Na agricultura brasileira, o Sistema Nacional de Crédito Rural (SNCR), teve grande relevância. Criado em 1965, através da Lei $\mathrm{n}^{\circ} 4.829$, tinha como objetivo o fortalecimento econômico dos produtores rurais, notadamente os pequenos e médios, quando se praticou taxas de juros subsidiadas no país. A partir do SNCR foram definidos, juntamente ao Banco Central do Brasil, Banco do Brasil, Banco do Nordeste do Brasil e Banco de Crédito da Amazônia, todos vinculados ao Banco Nacional de Desenvolvimento Econômico (BNDES), o crédito rural e ainda, a sociedade de crédito.

O financiamento subsidiado aos grandes produtores permitiu a expansão desenfreada e abusiva de insumos químicos, causando desperdício e degradação ambiental, em detrimento do financiamento de outros itens de custeio agrícola, tais como: aquisição de sementes melhoradas, especialmente para pequenos e médios produtores rurais (Sayad, 1984).

Há unanimidade entre autores brasileiros em afirmar que o crédito rural foi o mais importante instrumento, que se lançou no Brasil para promover a chamada modernização das atividades agropecuárias. No entanto, já foi também devidamente enfatizado que tal crédito beneficiou de maneira bastante desproporcional os grandes proprietários, constituindo-se numa das faces mais visíveis da estratégia de modernização conservadora (Szmrecsányi, 1997).

O agricultor familiar era tratado da mesma forma que o grande produtor rural, enfrentando as mesmas burocracias bancárias e disputando o crédito rural oficial com os demais produtores. Assim, o PRONAF quebra essa padronização de financiamento, que mesmo sob o rótulo de pronafiano, na verdade se transformou em política pública.

A agricultura familiar como categoria, segundo Abramovay (1992), deu-se a partir da observação de intensificação da agricultura em tempo parcial; dos sistemas de 
cooperativismos; dos sistemas de colonização; e da organização dos trabalhadores rurais face os avanços da industrialização.

Embora Lênin (1982) e Kautsky (1998) garantissem o desaparecimento da organização da produção familiar, foi possível constatar ao longo do século XX que as explorações agrícolas de base familiar não desapareceram. Ao contrário, se adequaram às novas formas de produção, absorvendo as inovações tecnológicas difundidas pelo sistema capitalista. Nesta esteira, Chayanov (1974) demonstra as potencialidades da produção familiar ao se adequar aos avanços tecnológicos, criando e recriando estratégias de sobrevivência, sob o prisma do utilitarismo.

Desse dado, a agricultura familiar e sua sustentabilidade é apresentada num discurso de desenvolvimento sustentável, clamando por uma reestruturação produtiva com base na fixação e retorno do homem ao campo. Sendo que essa sustentabilidade nas atividades agropecuárias deve provir da complementaridade no uso dos recursos naturais, associado à habilidade em harmonizar capacidade produtiva às necessidades de suprimento por alimentos e matérias primas. Sachs (1997) propõe cinco paradigmas, para atingir a sustentabilidade no campo: social, ecológica, cultura e geográfico. No entanto, em uma equação matemática. Enquanto que Souto (2005, p.8) procurou definir sustentabilidade somando pobreza, analfabetismo, injustiça social e degradação ambiental, com sinônimo de desenvolvimento humano negativo. A solução proveniente de uma nova relação rural-urbano mais equilibrada, possibilitaria um melhor nível de vida para a população rural, se nessa relação estiverem inseridas também as questões igualitárias para salários, acesso a terra, oportunidade de empregos, entre outros.

Análise realizada pelo Núcleo de Informações Econômicas, da Federação das Indústrias do Estado de Sergipe, apontou que o valor da produção agropecuária em Sergipe apresentou grande evolução nos últimos 25 anos. Entre 1995 e 2017, o valor da produção na agricultura sergipanas passou de R \$273,5 milhões para quase R \$ 2 bilhões, sendo que a agricultura familiar somou participação em quase um milhão de reais (IBGE, 2017). Fato que demonstra a importância dessa categoria produtiva no campo sergipano.

Para autores como Schroder (2006), Bastos (2006), Mattei (2006); o PRONAF B é resultado de um conjunto de medidas de cunho normativo tomadas pelo Governo Federal, visando à redução dos entraves burocráticos e à expansão do crédito. Nesse aspecto, um número expressivo de agricultores pobres, de acordo com a estratégia de inclusão social, norteou as políticas sociais das gestões governamentais. Uma característica desse programa 
seria a materialização da participação social, principalmente para o PRONAF B, através da conformação dos arranjos institucionais e que se apoia em circunstância decisivas.

Magalhães e Abramovay (2006) elencou três circunstâncias cruciais e de importância dessa modalidade de crédito para o Nordeste. Em primeiro lugar, a vontade governamental de ampliar o público do programa, em resposta à própria pressão social e também, de uma orientação mais geral que se relaciona à elevação do número de beneficiários dos programas de transferência de renda. Em segundo lugar, o trabalho de um conjunto de mediadores que constroem a clientela do programa, transmitindo-lhes as regras básicas, formas de organização de seu funcionamento e que zelam pela recuperação dos recursos emprestados. A estes dois fatores é preciso acrescentar um terceiro: o papel decisivo do Banco do Nordeste do Brasil ao criar o Agroamigo, no sentido de sensibilizar os autores locais para a importância da atribuição de crédito a população de baixa renda.

Diante os fatos, entende-se que os produtores rurais pertencentes à classe da Agricultura Familiar são reconhecidos por características básicas e próprias do sistema de vida e produção, entre os quais: 1) O trabalho e a gestão são predominantemente familiares; 2) O capital pertence à família; 3) O patrimônio e os ativos são objetos de transferência entre a própria família; 4) Os membros da família residem na própria unidade produtiva; 5) As unidades produtivas são responsáveis pela grande maioria da produção de alimentos básicos; 6) Vivem em terras com baixa produtividade e geralmente sem título de domínio; 7) Falta assistência técnica e as tecnologias utilizadas por essas famílias nas unidades produtivas são baixas; 8) Não possuem capacidade gerencial e tecnológica adequada às suas reais necessidades e 9) Enfrentam problemas de dificuldade para comercialização dos alimentos produzidos.

Segundo a Lei $\mathrm{n}^{\mathrm{o}}$. 11.326/2006 (BRASIL, LEI Nº. 11.326, 2006), considera-se agricultor familiar e empreendedor familiar rural aquele que pratica atividades no meio rural, e:

1 - Não detenha, a qualquer título, área maior do que quatro módulos fiscais;

2 - Utilize predominantemente mão de obra familiar nas atividades econômicas das suas unidades rurais ou empreendimentos;

3 - Tenha renda familiar predominanatemente originada de atividades econômicas vinculadas a propria unidade rural ou empreendimento;

4 - Dirija sua unidade rural ou empreendimento com sua família.

Deste modo, mais que representar categorias, a Agricultura Familiar através de gestão, propriedade e trabalho familiar, é considerada a base para o desenvolvimento de um projeto 
econômico viável para o espaço rural brasileiro, em função da consciência que ela pode ter em alguns setores da oferta agropecuária. Isso se explica no fato de sua preocupação principal está centrada na diversificação produtiva, na integração as demandas de mercado e na geração de renda.

Por conseguinte, a agricultura familiar, associada à dimensão espacial, busca orientar as funções da agricultura e a sua consolidação como fornecedora de alimentos, de matériasprimas, de divisas e de sustentabilidade ambiental, uma vez que promove a preservação da paisagem e da cultura local. Decorrente dessas características, a agricultura familiar pode estimular o desenvolvimento rural numa dimensão territorial, em que atividades agrícolas e não agrícolas tendem a ser integradas a nível local, basta haver estímulos em políticas, como o PRONAF.

Assim, a agricultura familiar é uma categoria social que nos últimos anos tem representado um conjunto social diverso e passível de diferenciação espacial, que comunga sempre de atributos comuns, a exemplo da: "[...] família como proprietária dos meios de produção, o trabalho na terra, modalidades de produção e manifestação de valores e tradições (patrimônio sociocultural) em torno da e para a família” (TEDESCO, 2001, p.11). Essa categoria manifesta nos últimos anos a evolução dos processos sociais, perpassando as mudanças no meio rural agrícola brasileiro, entre as quais a afirmação, o reconhecimento e a legitimação dessa categoria juntamente ao Estado brasileiro, que demonstrou "fé" na sua importância socioeconômica, contribuindo assim, para seu aparecimento nas estatísticas oficiais a partir de 2006.

\section{O Agroamigo e a Qualificação do Crédito do Pronaf B}

O Programa Nacional de Fortalecimento da Agricultura Familiar (PRONAF) foi criado através do Decreto $n^{\circ}$ : 1.946, de 28 de junho de 1996 (BRASIL. LEI N 1.996, 2012), tendo suas normas consolidadas na Resolução ${ }^{\circ}$ 2.310, de 29 de agosto de 1996. Vinculou-se institucionalmente ao Ministério de Desenvolvimento Agrário (MDA) ${ }^{2}$, sendo nesse momento

\footnotetext{
${ }^{2}$ Extinto em 12 de maio de 2016 através da medida provisória $\mathrm{n}^{\circ} \underline{726}$, que alterou e revogou a Lei $\mathrm{n}^{\circ} 10.683$, de 28 de maio de 2003, transferindo na época suas competências para o Ministério do Desenvolvimento Social (MDS).
} 
gestado pelo Ministério da Agricultura, Pecuária e Abastecimento (MAPA), através da Secretaria de Agricultura Familiar e Cooperativismo (SAF) ${ }^{3}$.

O PRONAF persiste representando a culminância de um processo liderado pelas organizações sociais dos trabalhadores rurais brasileiros que pôde se materializar em termos de política pública, no âmbito do governo federal (BRASIL. Resolução $\mathrm{n}^{\circ}$ 2.310, 2012). Apesar de desde 2019, o mesmo passa por modificações no sentido de estimular o cooperativismo, com auxílios financeiros mais amplos, inclusive em nível individual, visando um maior processamento dos produtos advindos da terra (MAPA, 2019).

Em 2006, foi sancionada a Lei n ${ }^{\circ} 11.326$, de 24/07/2006, que estabelece as diretrizes para a formulação da Política Nacional da Agricultura Familiar e Empreendimentos Familiares Rurais, passando a reconhecer a agricultura familiar como segmento produtivo, garantindo-se assim, a institucionalização de política pública específica para esse setor (BRASIL. LEI nº. 11.326, 2012).

O PRONAF tem como propósito fortalecer a agricultura familiar, mediante o financiamento de infraestrutura de produção e de serviço agropecuários; e atividades rurais não agropecuárias, com o emprego direto da força de trabalho do produtor rural e de sua família, objetivando a geração de trabalho e manutenção do homem no campo.

O público alvo do PRONAF é classificado por grupos ou modalidades próprias no que se refere às taxas de juros, limites de financiamento do crédito. Para efeito de classificação dos agricultores familiares nos grupos do PRONAF, são excluídos da composição da renda familiar os beneficiários de programas sociais e detentores de proventos da Previdência Rural.

O Banco do Nordeste do Brasil S.A (BNB), na qualidade de principal financiador do PRONAF na região Nordeste, norte de Minas Gerais e norte do Espírito Santo, operacionaliza o programa na perspectiva de desenvolvimento rural. Essa proposta tem como objetivo contribuir para melhorar a articulação das ações do governo federal, visando criar e fortalecer as condições para o aumento da capacidade produtiva no meio rural, a melhoria da qualidade de vida desses agricultores, bem como estimular o exercício da cidadania (Maciel, 2009).

Os agricultores familiares mais pobres, cuja renda familiar anual bruta não ultrapassava R\$ 6 mil reais, eram atendidos no âmbito do PRONAF B até 2004. Nesse ano, essa linha de crédito apresenta altos índices de inadimplência e frequentemente, operava com

\footnotetext{
${ }^{3}$ Secretaria criada em 2 de janeiro de 2019, pelo Decreto $n^{\circ}$ 9.667, com a transferência das competências da Secretaria Especial da Agricultura Familiar e do Desenvolvimento Agrário (Sead), até então da Casa Civil da Presidência da República.
} 
projetos elaborados em lote, sem atender, portanto, as necessidades peculiares aos empreendimentos de cada família beneficiária.

Conforme Guanziroli (2006), o PRONAF surge numa época na qual o elevado custo e a escassez de crédito eram os principais problemas enfrentados pelos agricultores, em particular os familiares. $\mathrm{O}$ argumento essencial era de que os produtores familiares, descapitalizados e com baixa produtividade, não estariam em condições de tomar recursos a taxas de mercado para realizar os investimentos que garantiriam a elevação da produtividade. E seus rendimentos não seriam compatíveis e nem suficientes o bastante para reembolsar empréstimos tomados em condições comerciais.

Atualmente, o PRONAF persiste sendo o principal instrumento de financiamento dos produtores rurais, sobretudo dos pequenos produtores, tradicionalmente excluídos do crédito agrícola. É um significativo avanço, ao considerar as formas tradicionais de financiamento da agricultura brasileira. Antes de sua criação, o financiamento ao pequeno produtor restringia-se quase exclusivamente aos recursos administrados pelo Programa de Crédito Especial da Reforma Agrária (Procera), que era destinado aos beneficiários da reforma agrária e que foi extinto em 1999.

Segundo o Manual de Crédito Rural (MCR), o PRONAF destina-se ao apoio financeiro das atividades agropecuárias e não agropecuárias, exploradas mediante emprego direto da força de trabalho dos agricultores familiar, assentados de reforma agrária, quilombolas, pescadores artesanais, aquicultores, maricultores, piscicultores, extrativistas, silvicultores, ribeirinhos e indígenas. Os créditos podem destinar-se a custeio e investimento de forma individual ou coletiva. Entendendo-se por atividades não agropecuárias os serviços relacionados com turismo rural, produção artesanal, agronegócio familiar e outras prestações de serviços no meio rural, que sejam compatíveis com a natureza da exploração rural, da mão de obra familiar.

As modalidades do PRONAF envolvem quatro linhas de atuação, conforme o Manual de Crédito Rural e Mattei (2001), que são: 1 - Financiamento de Infraestrutura e Serviços Municipais - voltados para a melhoria da rede de infraestrutura dos municípios, através do financiamento de obra e serviços necessários ao fortalecimento da agricultura familiar. 2 Capacitação e Profissionalização dos Agricultores Familiares e Técnicos - visa proporcionar novos conhecimentos aos agricultores familiares e às suas organizações sobre o processo de produção e gestão das propriedades. 3 - Financiamento da Produção da Agricultura Familiar (Crédito Rural) - tem como objetivo oferecer apoio financeiro aos agricultores familiares por meio de linhas de crédito específicas de custeio e investimento. 
Os recursos disponibilizados ao PRONAF são do Fundo Constitucional de Financiamento do Nordeste (FNE), do Fundo Constitucional de Financiamento do Norte (FNO), do Fundo Constitucional de Financiamento do Centro-Oeste (FCO), da Secretaria do Tesouro Nacional (STN)/Orçamento Geral da União (OGU), da Pouponça Rural, da Exigibilidade Bancária, do Fundo de Amparo ao Trabalhador(FAT e do Banco Nacional de Desenvolvimento (BNDES) ${ }^{4}$.

Por conseguinte, o PRONAF se divide entre custeio, com dois grupos (Pronaf Custeio e Pronaf A/C) e investimento, no qual há 14 grupos de crédito (2019), entre os quais: 1-Pronaf

Mais Alimentos, 2-Pronaf Agroindústria, 3-Pronaf Floresta, 4-Pronaf Semiárido, 5Pronaf Mulher, 6- Pronaf Jovem, 7-Pronaf Industrialização de Agroindústria Familiar, 8Pronaf Cota- Parte, 9-Pronaf "B”, 10-Pronaf Agroecologia, 11- Pronaf ECO Sustentabilidade Ambiental, 12-Pronaf A, 13- PronaF Grupo A, 14- Pronaf Produtivo Orientado. Dentre todos esses grupos e modalidades, focalizar-se-á para efeito de estudo o grupo B (Agroamigo), haja vista ser estratégico para os agricultores familiares pobres, ao valorizar o potencial produtivo deste público e permitir estruturar e diversificar a unidade produtiva. Pode financiar atividades agrícolas e não agrícolas geradoras de renda.

O público-alvo do Pronaf B são agricultores familiares com renda bruta anual de até $\mathrm{R} \$ 23.000,00$. O crédito é de até $\mathrm{R} \$ 7.500,00$ limitado a três operações de $\mathrm{R} \$ 2.500,00^{5}$; taxas de juros efetivas de $0,5 \%$ ao ano. O bônus de adimplência pode ser de até $25 \%$, aplicados em cada operação até o valor acumulado de R \$ 7,5mil (R \$ 15 mil, com PNMPO) ou de 40\% - nos municípios do semiárido da área da Sudene, quando adotado a metodologia do PNMPO, com prazo de pagamento de até 2 anos (MAPA, 2019).

O PRONAF B, na região Nordeste, tem sido trabalhado pelo Banco do Nordeste como Programa Agroamigo, operacionalizado em parceria com o Instituto Nordeste de Cidadania (INEC) e através da Secretaria de Agricultura Familiar e Cooperativismo (SAF), vinculada ao Ministério da Agricultura, Pecuária e Abastecimento (MAPA). Trata-se de uma iniciativa pioneira no Brasil que visa à concessão de financiamento para área rural, adotando metodologia própria de atendimento, cuja principal premissa consiste na concessão de crédito orientado e acompanhado.

Cabe ressaltar que os agricultores clientes do Agroamigo poderão desenvolver qualquer atividade geradora de renda no campo ou em aglomerado urbano próximo, sejam

\footnotetext{
${ }^{4}$ https://www3.bcb.gov.br/mcr

${ }^{5}$ Quando utilizar a metodologia do Programa Nacional de Microcrédito Produtivo Orientado-PNMPO, as operações são de até $\mathbf{R} \$ \mathbf{5}$ mil, chegando o crédito a $\mathbf{R} \$ 15$ mil.
} 
agrícolas, pecuárias ou outras atividades não agropecuárias no meio rural, como turismo rural, agroindústria, pesca, serviços no meio rural e artesanato.

Essa metodologia atende, de forma pioneira no Brasil, a milhares de agricultores familiares classificados como PRONAF B, ou seja, que obtiveram renda bruta nos últimos 12 meses de até R \$ 23 mil reais, explorem área de até quatro módulos rurais e utilizem mão de obra familiar. Para esse grupo, os financiamentos vão até o montante de $\mathrm{R} \$ 5.000,00$. Em 2012, o Agroamigo iniciou a expansão da metodologia de microcrédito para outros Grupos e Linhas do PRONAF, com exceção dos Grupos A e A/C.

Neste tocante, seriam beneficiários do PRONAF, os produtores que compõem as unidades familiares de produção rural e que comprovarem seu enquadramento mediante apresentação da Declaração de Aptidão ao PRONAF (DAP), emitida pelos órgãos oficiais de assistência técnica dos Estados ou pelos Sindicatos de Trabalhadores Rurais.

Deste modo, o respectivo programa de microfinanças rurais é um elemento central das políticas públicas de acesso ao crédito às camadas mais vulneráveis da população rural, que sempre estiveram à margem do sistema bancários.

Bittencourt (2003, p. 9) ao se referir à política de crédito rural adotada historicamente pelo Brasil, observa que, diferentemente de outros países que utilizaram o subsídio ao crédito para reduzir a pobreza, os objetivos centrais brasileiros têm sido aumentar a oferta de alimentos e modernizar a agricultura, privilegiando os pequenos agricultores e reduzindo a pobreza rural.

A integração do Agroamigo com os programas do Governo Federal alicerçara o acesso de agricultores familiares a produtos e serviços bancários, a canais de comercialização e sustentabilidade dos empreendimentos. Entre os programas que atuam conjuntamente a causa da agricultura familiar estão:

1) Programa de Aquisição de Alimentos - PAA, instituído pela Lei nº10.696, de 2003. Por meio deste, o governo adquire alimentos dos (as) agricultores (as) familiares e doa parte para pessoas em risco alimentar, por meio de instituições reconhecidas, além de realizar formação de estoques.

2) Merenda Escolar - No Programa Nacional de Alimentação Escolar - PNAE, os recursos do Governo Federal são repassados em caráter suplementar aos Estados, Distrito Federal e Municípios, para a aquisição de gêneros alimentícios destinados a merenda escolar dos estudantes da rede pública. A Lei no 11.947, de 2009, determina que no mínimo 30\% dos recursos deverão ser utilizados na aquisição de gêneros alimentícios diretamente da agricultura familiar. 
3) Zoneamento Agrícola - O Zoneamento Agrícola de Risco Climático é um instrumento de política agrícola e gestão de risco na agricultura, ciclo de plantio, com o objetivo de minimizar os riscos relacionados aos fenômenos climáticos, como geadas e escassez de água, por exemplo, permitindo a cada município identificar a melhor época de plantio das culturas.

4) Proagro Mais - Programa governamental que visa amortizar operações de custeios agrícola e indenizar parcela da renda que seria gerada no caso de ocorrer um evento adverso da natureza que afete as lavouras. De outra parte, o Proagro Mais Investimento assegura cobertura adicional para pagamento de parcelas de investimento agropecuário, aos agricultores familiares que tenha uma operação de custeio agrícola coberto pelo Proagro Mais.

5) Programa de Garantia de Preços para a Agricultura Familiar - PGPAF - Consiste na concessão de um bônus aos agricultores familiares que contraírem financiamento de investimento ou custeio, quando o preço de mercado do produto financiado estiver abaixo do custo de produção (preço de garantia). A adesão é feita automaticamente no momento da contratação do financiamento de custeio.

De acordo com Maciel (2009, p.16), as dificuldades encontradas no PRONAF B, antes da criação do Agroamigo, eram atribuídas:

[...] à padronização de projetos: as propostas de financiamento eram Formuladas à revelia das peculiaridades de cada agricultor e da atividade por ele desenvolvida, num cenário da falta de acompanhamento e elevada incidência de desvio de crédito. Além desses fatores, o tempo de espera incidência de desvio de crédito. Além desses fatores, o tempo de espera decorrido entre a solicitação e a liberação do crédito chegava a ultrapassar um ano. O custo da transação para o agricultor era elevado, sobretudo devido aos sucessivos deslocamentos às instituições mediadoras do programa. A falta de informação e até de documentos como cédula de identidade e Cadastro de Pessoas Físicas (CPF), agravavam esse quadro.

Para Abramovay (2005, p.57),

Há uma diferença radical entre a maneira como se alocam os recursos do Pronaf e a experiência do Banco do Nordeste do Brasil com o microcrédito. O Banco do Nordeste opera com um assessor de crédito que responde pela qualidade de uma determinada carteira de crédito. Ele conhece seus clientes e zela não só por fazerlhes chegar recursos, mas, sobretudo pelo retorno do dinheiro aplicado e, portanto, pela capacidade de este dinheiro traduzir-se, efetivamente, em geração de renda e combate a pobreza.

Considerando a evolução das operações e o montante liberado pelo programa Agroamigo nos exercícios de 2005 a 2019, foram contratadas 5.167.129 operações, totalizando mais de R \$ 17,3 milhões em valores aplicados no Nordeste brasileiro (Gráfico 1). 
Gráfico 1- Agroamigo - Quantidade de Operações e Valares Contratados (R\$ Mil).

\section{0}

2500000

2000000

1500000

1000000

500000

0

200520062007200820092010201120122013201420152016201720182019

घuantidade de operações Valor Contratado R \$ Mil)

Fonte: Relatório do Programas de Microfinanças do Banco do Nordeste (BNB, 2019).

O saldo acumulado das operações do Agroamigo até dezembro de 2019, no que se refere à quantidade de operações, está distribuído nos seguintes setores: Agricultura (13\%), Pecuária (82\%), Extrativismo (1\%), além de atividades não agropecuárias, caso do setor de serviços (4\%) desenvolvido no meio rural, exemplificado na prestação de serviços de beleza, tanto para homens quanto para mulheres (gráfico 2). Dessa forma, verifica-se uma grande quantidade de operações na atividade pecuária, justificada pela tradição persistente na região.

Diante dos respectivos dados, valida-se o uso do Agroamigo em atividades não agropecuárias, alterando o perfil maximizante da produção agropecuária rural de muitas localidades e agregando renda diferenciada ao orçamento dos agricultores familiares. Este fenômeno que vem sendo chamado de pluriatividade reveste-se de particular importância num cenário de produção agrícola em declínio para os agricultores mais pobres (GROSSI, SILVA, 2002).

Gráfico 2- Agroamigo - Quantidade Operações por Setor de Atividade 


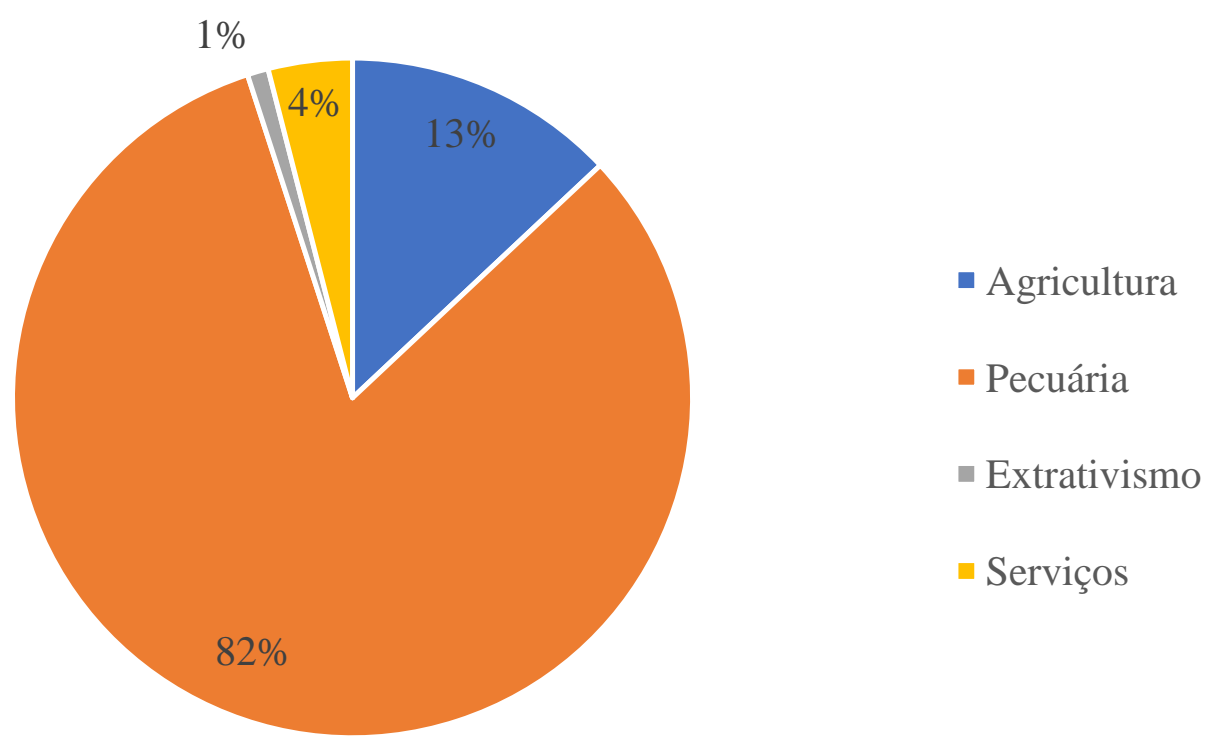

Fonte: Relatório do Programas de Microfinanças do Banco do Nordeste (BNB, 2019).

De acordo com a metodologia do Agroamigo, uma das premissas de atendimento ao agricultor familiar é a concessão do crédito de forma orientada, gradual e sucessiva, dentro de um processo de educação financeira. Esse processo vem sendo perseguido, haja vista que os valores contratados estão divididos em seis faixas de valores, com destaque para as contratações nas faixas de $\mathrm{R} \$ 4.000,01$ a $\mathrm{R} \$ 10.000,00$ e de $\mathrm{R} \$ 2.001,00$ a $\mathrm{R} \$ 3.000,00$ com participação de $62 \%$ e de $18 \%$ respectivamente (gráfico 3 ).

Gráfico 3- Contratações por Faixa de Valores Contratados.

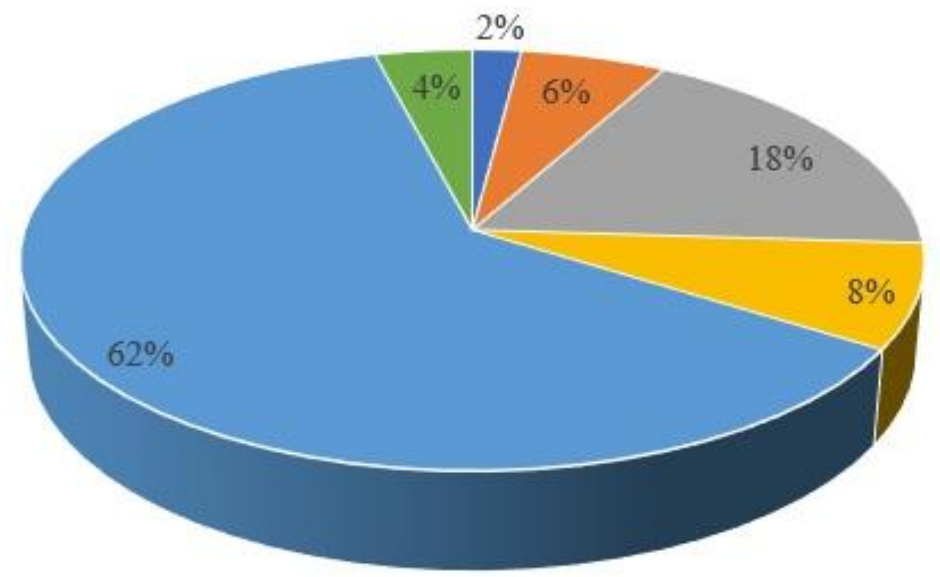

- RS $1.000,00$

- R\$1.000,01 a R\$2.000,00

- R\$2.000,01 a R\$3.000,00

= R\$3.000,01 a R\$4.000,00

- R\$4.000,01 a R\$10.000,00

- 10000,01 a R\$15.000,00

Fonte: Relatório do Programas de Microfinanças do Banco do Nordeste (BNB, 2019). 
Nessa perspectiva, o prazo de pagamento deve ser adequado à atividade desenvolvida pelo agricultor familiar, num prazo de até dois anos para pagamento. Cabe informar que, no modelo tradicional de operacionalização do PRONAF B, esse prazo é normalmente padronizado e sempre de dois anos. O mesmo, em 2019, agregou um índice de adimplência de $95,16 \%$, ao tempo que contemplou 158.145 novos contratantes (BNB, 2019).

Outro aspecto a ser lembrado é a participação do público feminino na carteira ativa do Agroamigo. Em 2005, as mulheres contribuíram com 43\% das contratações, evoluindo para 48\% em 2019. Assim, percebe-se que, de fato o Agroamigo tem colaborado para o acesso das mulheres às políticas de crédito no meio rural.

Segundo Magalhães e Abramovay (2006, p. 17),

Financiamento de atividades tradicionais femininas acaba sendo um estimulo à diversificação e à inserção mercantil de produtos e serviços que não faziam parte dos mercados na maior parte dos sertões nordestinos. É na valorização do "trabalho invisível" das que ocorrem as poucas, no entanto expressivas experiências de inovação.

Desse modo, a grande participação feminina, no âmbito do Agroamigo, além de possibilitar a redução das desigualdades de gênero no meio rural, permite a diversificação das atividades não agrícola no meio rural.

\section{Considerações Finais}

O PRONAF tem sido importante instrumento para o financiamento da agricultura familiar e tem um papel muito importante na dinamização do espaço rural nordestino e no estabelecimento de relações com o urbano. Aspecto que contribui para produção dos alimentos que atendem à população do país, permite uma distribuição demográfica mais equilibrada, haja vista fixar o agricultor familiar e seus familiares no campo.

Para que a agricultura familiar apresente maior dinamismo nos sistemas de produção é preciso investir na assistência técnica, gestão, comercialização e nas relações associativas desses agricultores. Neste sentido, é preciso incentivar o prolongamento e o envolvimento do agricultor familiar no direcionamento social e político do PRONAF, principalmente entre os assentamentos e comunidades rurais, visando retorno compensatório que garanta melhores condições de vida aos agricultores e a suas famílias. Para isso será necessário envolvimento nos conselhos municipais e estaduais, associações, cooperativas para fiscalizar e cobrar melhor distribuição das políticas públicas para suas localidades. 
É possível afirmar que o PRONAF B (Agroamigo), é uma linha de microcrédito criada com o objetivo de combater a pobreza rural, que tem se constituído em uma importante estratégia para o programa. Desse modo, o PRONAF B (Agroamigo) tem crescido significativamente, apesar de variações ano a ano, tanto em volume de recursos financiados, como em quantidades de contratos firmados.

O Agroamigo possuí um modelo diferenciado do modelo tradicional disponibilizado pela maior parte das agências bancárias, com um conceito de atendimento focado no Assessor de Microcrédito, de preferência Técnico Agrícola. A metodologia empregada, exclusivamente pelo Banco do Nordeste (BNB), oferece subsídios para o aperfeiçoamento do programa, seja na elaboração ou na execução, sob a perspectiva da efetividade política e social do agricultor familiar.

Devido à sua significativa participação no financiamento da agricultura familiar, o BNB vem se firmando como um importante parceiro do Governo Federal na implementação das políticas de apoio à agricultura familiar no Nordeste. Dessa forma, é que o Banco operacionaliza o Programa Nacional de Fortalecimento da Agricultura Familiar (PRONAF) desde sua criação, em 1996.

Portanto, fica evidente a necessidade de novas análises a respeito do tema, na perspectiva socioeconômica do processo de organização da agricultura familiar, levando em consideração novos elementos que integram essa modalidade de crédito. Sendo assim, a proposta é que esse trabalho se desdobre em novos olhares e novas possibilidades analíticas, contribuindo para o ecletismo analítico dos impactos do microcrédito rural no espaço rural nordestino.

\section{Referências}

ABRAMOVAY, R. Paradigmas do capitalismo agrário em questão. São Paulo: HUCITEC/UNICAMP, 1992.

ABRAMOVAY, R. Finanças de proximidade e desenvolvimento territorial no semi-árido brasileiro. MDA:FIDA, Projeto Dom Helder Câmara, 2001, mimeo.

ABRAMOVAY, R. Laços financeiros na luta contra a pobreza. São Paulo: Annablume, 2004.

ABRAMOVAY, R. Alcance e limites das finanças de proximidade no combate à inadimplência: O caso do Agroamigo. O caso do Agroamigo. São Paulo: FIPE, 2008 . (Texto para Discursão, n. 10). 
ABRAMOVAY, R.; MAGALHÃES, R. Acesso, uso e sustentabilidade do Pronaf B. Disponível em <www.econ.fea.usp.br/abramovay/>. Acesso 04 de fevereiro de 2014.

ABRAMOVAY, R.; VEIGA, J. E. Novas instituições para o desenvolvimento rural: $\mathbf{O}$ caso do Programa Nacional de Fortalecimento da Agricultura Familiar (PRONAF). IPEA, 1999.

BNB. Manual Básico: operações de crédito programas especiais: Programa Nacional de Fortalecimento da Agricultura Familiar: Microcrédito Produtivo Rural. PRONAF: grupo Fortaleza 2009. 13p.

BNB. Manual para formação em microcrédito rural: manual do assessor de microcrédito rural. Fortaleza, 2006. 201 p.

BNB.. Manual de procedimentos: microcrédito rural: Agroamigo. Fortaleza, 2008.49 p.

BNB. Agricultura Familiar: grupos e linhas [S.I], [20--]. Disponível em: WWW.bnb.gov.br. Acesso em 28/03/2014.

BNB. Programa Nacional de Fortalecimento da Agricultura Familiar Pronaf. Relatório de Resultados. Fortaleza, 2010. 68p.

BNB. Relatório do Programas de Microfinanças do Banco do Nordeste. Fortaleza, 2019. Disponível em: https://www.bnb.gov.br/documents/165130/0/2019.RelatoriodeMicrofinancas.pdf/a86543703761-b943-4e02-f51f951d834c. Acesso em 10/04/2020.

BNB. Agroamigo consciente: Resultado com qualidade em nossas mãos. Fortaleza, 2019. Disponível em: https://www.bnb.gov.br/documents/165130/165426/Relat\%C3\%B3rio+Gerencial++Agroamigo.pdf/429d7e39-665c-e30a-c12b-13f31af7c656. Acesso em 10/04/2020.

BASTOS, Fernando. Ambiente institucional no financiamento da agricultura familiar. São Paulo: Polis, 2006.

BITTENCOURT, G. Microcrédito e microfinanças no governo Lula. 2005. Disponível em $<$ http://fazenda.gov.br/portugues/documentos/2005/apresentacao\%20Microcredito $\% 20$ Novo. ppt $>$. Acesso em 8 de março de 2014.

BITTENCOURT, G, Abrindo a caixa preta - o financiamento da agricultura familiar no Brasil. 2003. Dissertação (Mestrado em Desenvolvimento Econômico, Espaço e Meio Ambiente) - Universidade Estadual de Campinas, Campinas, 2003).

BRASIL. Ministério do Desenvolvimento Agrário. Abordagem territorial. Brasília, DF, 2009. Disponível em http://comunidades.mda.gov.br/portal/sdt/acesso em 06 de março 2014.

BRASIL. Ministério do Desenvolvimento Agrário. Agricultura Familiar e o censo agropecuário 2006. Brasília, DF, 2009. Disponível em: http:/w.w.w.gov.br/publicações. Acesso em 06 de março 2014,

BNB. Lei 11.326, de 24 de julho de 2006. Estabelece as diretrizes para a formulação da Política Nacional da Agricultura Familiar e Empreendimentos Familiares Rurais. Diário Oficial [da] República Federativa do Brasil, Brasília, DF, 24 de jul. 2006. 
CHAYANOV, Alexander. La organización de la unidad económica campesina. Buenos Aires: Nueva Visión, 1974.

FURTADO, C. Formação econômica do Brasil. 17. Ed. São Paulo: Nacional, 1980.

GUANZIROLI, C.E. Pronaf dez anos depois: resultados e perspectivas para o desenvolvimento rural. In CONGRESSO SOBER, 44., 2006, Fortaleza. Anais... Fortaleza, 2006. Disponível em:http://www.anpec.org.br/encontro2006/artigos/A06a169.pdf.Acesso em 05 março.2014.

KAUTSKY, Karl. A questão agrária. São Paulo: Nova Cultural. 1998.

IBGE. Censo Agropecuário. Rio de Janeiro: 2006. Disponível em < ftp://ftp.ibge.gov.br/Censos/Censo_Agropecuario_2006/Censo_Agropecuario_2006.zip>. Acesso em 12 de janeiro de 2013.

IBGE. Censo Agropecuário. Rio de Janeiro: 1995. Disponível em < ftp://ftp.ibge.gov.br/Censo_Agropecuario/Censo_Agropecuario_1995 96/Sergipe/>. Acesso em $12 \mathrm{de}$ janeiro de 2019.

IBGE. Censo Agropecuário. Rio de Janeiro: 2017. Disponível em < https://sidra.ibge.gov.br/tabela/6898>. Acesso em 12 de janeiro de 2019.

LENIN, V. I. Confusão entre pedagogia e política. In: LENIN, V. I. Obras completas. 5. ed. Em Cinquenta e Cinco Tomos. Moscou: Progresso, 1982. t. 10. p. 370-373.

LOPES, E. S. A. (Org.). Impactos do Pronaf B nos Municípios de São Cristóvão e Itabaiana, Estado de Sergipe: Para Além da Dimensão Econômica.

UFRN/IICA/NEAD/FUNTEC. Projeto de Pesquisa: Impactos do Pronaf B sobre o meio rural na região Nordeste. Aracaju, 2007.

MACIEL, Iracy S. R. Avaliação da metodologia do Agroamigo em Caucaia-CE. Fortaleza: Banco do Nordeste do Brasil, 2009. 272 p. (Série BNB Teses e Dissertações, n. 17).

MAGALHÃES, R. e ABRAMOVAY, R. Acesso, uso e sustentabilidade do Pronaf B. São Paulo: MDA/FIPE, 2006. 25p.

MAPA. Mudanças no Pronaf aumentam limite de financiamento para agricultura familiar. Publicado em 31.10.2019. Disponível em<https://www.gov.br/ptbr/noticias/agricultura-e-pecuaria/2019/10/mudancas-no-pronaf-beneficiamcooperativas-da-agricultura-familiar >. Acesso em 10 de abril de 2020.

MAPA. Pronaf: Resumo das linhas de crédito, 2019-2020. Disponível em < https://www.gov.br/agricultura/pt-br/assuntos/camaras-setoriaistematicas/documentos/camaras-setoriais/palma-de-oleo/2019/29a-ro-1/pronaf-resumo-daslinhas-de-credito-2019-2020-convertido.pdf/view>. Acesso em 10 de abril de 2020.

MATTEI, Lauro. Programa Nacional de Fortalecimento da Agricultura Familiar (PRONAF): concepção, abrangência e limites observados, In: Encontro da Sociedade Brasileira de Sistemas de Produção, 4., 200', Belém, Anais... Belém, 2001. 
MATTEI, Portal da Secretaria da Agricultura Familiar. Balanço Crítico e Estratégico do Pronaf. Palavras do Secretário. Brasília (DF), dezembro, 2007. Disponível em <http://www.mda.gov.br/saf/index.php?sccid=274>. Acesso em 12 de fevereiro de 2014.

MATTEI, Novas Regras do Pronaf. Brasília (DF), 03 de abril de 2008. Disponível em <http://www.mda.gov.br/saf>. Acesso em 12 de fevereiro de 2014.

MATTEI, Referências para o desenvolvimento territorial sustentável. Brasília: MDA, 2003. Disponível em: <http://www.nead.gov.br>. Acesso em 01 de agosto de 2012.

MATTEI, CONDRAF. Diretrizes Para o Desenvolvimento Rural Sustentável. 2006. Disponível em

$<$ http://www.faper.org.br/index.php?option=com_docman\&task=doc_download\&gid=5\&Ite

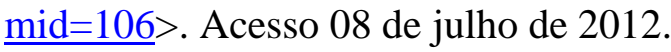

MATTEI, Impactos do PRONAF: análise de indicadores. Brasília: MDA/NEAD, 2005.

PRADO Júnior. Caio. História econômica do Brasil. São Paulo: Brasiliense, 2004.

SACHS, I. Espaços. Tempos e estratégias do desenvolvimento. 1997.

SAYAD. J. Crédito rural no Brasil: avaliação das críticas e das propostas de reforma. São Paulo, SP: Pioneira, 1984.

SCHRODER, M. Agricultura Familiar e Crédito do "Milinho": Os caminhos do Pronaf pelos Sertões Mineiros. São Paulo, 2006. Mimeo.

SCHWAETZMAN, S. As causas da pobreza. Rio de Janeiro: FGV, 2004

SCHWAETZMAN, S.; RAMOS, P.O papel das políticas governamentais na modernização da agricultura brasileira. In: SZMRECSÁNYI. T.: SUZIGAN. W. (Org). História econômica do Brasil contemporâneo. São Paulo: Hucitec, 1997.

SCHNEIDER, Sergio. Políticas Públicas, Pluriatividade e Desenvolvimento Rural no Brasil. Porto Alegre: UFRGS, 2001, p. 114.

SILVA, A. G. da (COORD.). Impactos do Pronaf B sobre o meio rural na Região Nordeste. UFRN/IICA/NEAD/FUNTEC. Natal (RN), março de 2007.

SOTO, W. H. G. A Produção do Conhecimento sobre o Mundo Rural no Brasil: As Contribuições de José de Souza Martins e José Graziano da Silva. Santa Cruz do Sul: Edunisc, 2002. 